Federal do Piauí em Teresina, Brasil, realizou-se pela primeira vez em modo não presencial. Reuniu estudantes do ensino secundário de 11 países (BRA, CRI, ECU, SLV, ESP, GTM, MEX, PER, PRT, URY, VEN). A prova foi dividida em dois exames, um teórico e outro prático, de 5 h cada: a comissão organizadora foi pioneira na realização de um exame prático online através de filmagens de experiências laboratoriais. A participação portuguesa nas OIAQ completa 20 anos; há 19 anos a obter medalhas e menções honrosas continuadamente.
$>$ Diana Pinto diana@ua.pt

$>$ João Pereira miguel.joao@ua.pt

$>$

Vasco Batista vfb@ua.pt

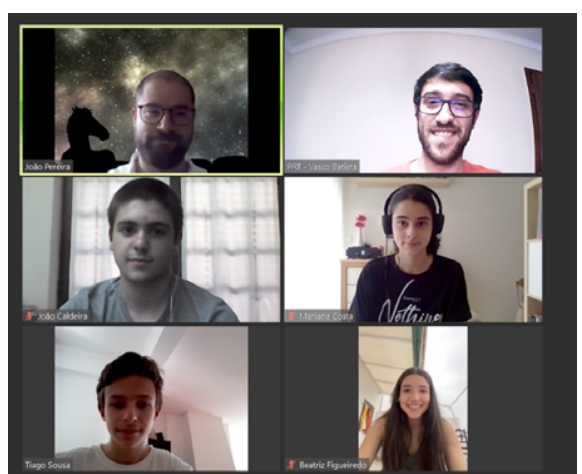

\title{
Prémio Madinaveitia-Lourenço de 2021 Atribuído a João Mano
}

O Prémio Madinaveitia-Lourenço de 2021 foi atribuído a João Mano, Professor Catedrático do Departamento de Química da Universidade de Aveiro e investigador do CICECO - Instituto de Materiais de Aveiro. As suas áreas atuais de investigação incluem Materiais Bioinspirados com o desenvolvimento de novas classes de materiais e processos baseados em polímeros de origem natural, Engenharia Celular e de Tecidos para o desenvolvimento de implantes híbridos através da integração de biomateriais e Plataformas Nano/ Micrométricas para biomedicina recorrendo a nano e microtecnologias de ponta para aplicações biomédicas, incluindo diagnóstico e terapia.

Este prémio Luso-Espanhol de Química, instituído em parceria pela Sociedade Portuguesa de Química e pela Real Sociedad Española de Química, é atribuído anualmente, e em alternância, a químicos portugueses e espanhóis com projeção internacional. A instituição deste prémio destina-se a recordar dois químicos notáveis: Antonio San Quintín Madinaveitia y Tabuyo (18901974) e Agostinho Vicente Lourenço (1822-1893).

A lista de todos os premiados pede ser encontrada na página da SPQ em spq.pt/premios/luso-espanhol/lista.

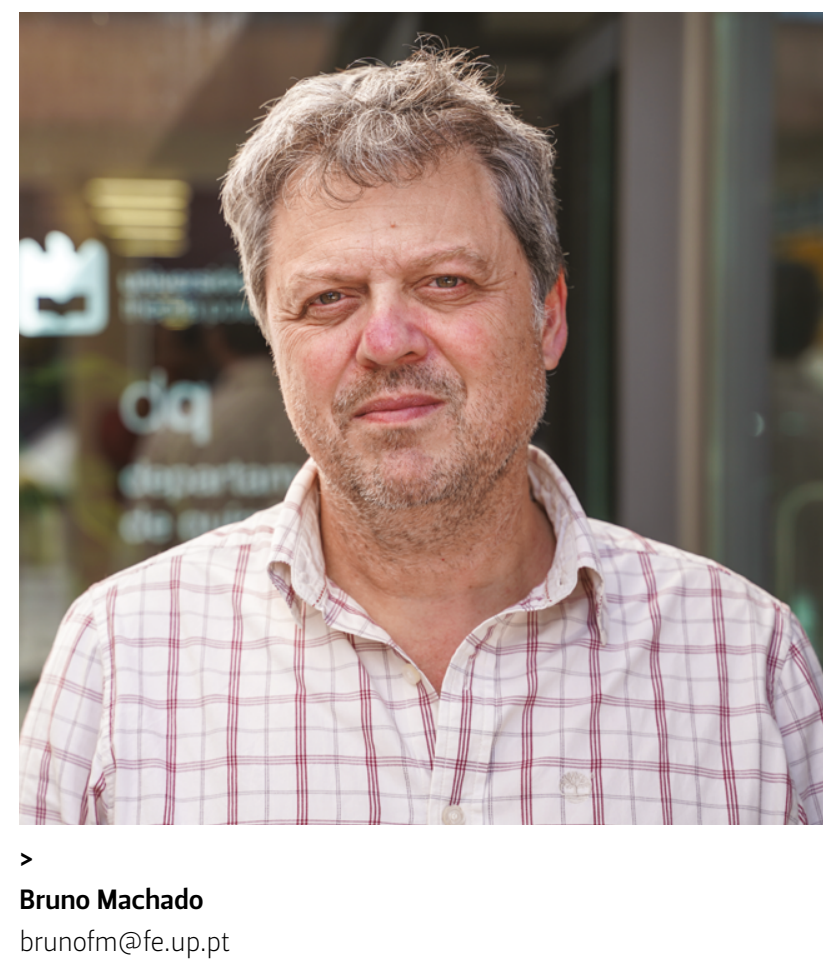

\section{Prémio Ramôa Ribeiro 2021 Atribuído a Vânia Calisto}

A Divisão de Catálise e Materiais Porosos (DCMP) da Sociedade Portuguesa de Química (SPQ) instituiu o Prémio Ramôa Ribeiro para ser atribuído bienalmente durante o Encontro da DCMP (adiado de 2020 para
2021 devido à pandemia da COVID-19).

Este prémio é concedido a um investigador jovem que, pela obra científica produzida em Portugal, tenha contribuído significativamente para o avanço 
da catálise e materiais porosos em qualquer das suas áreas de intervenção.

O júri, constituído pelo presidente da DCMP, pela Professora Filipa Ribeiro, pelo Professor Helder Gomes e pelo Professor Mário Calvete decidiu, por unanimidade, atribuir o Prémio Ramôa Ribeiro 2021 à candidata Vânia Maria Amaro Calisto da Universidade de Aveiro.

A premiada é Investigadora Auxiliar e Coordenadora do grupo de investigação Analytical Sensors and Applied Eco-Chemistry (ASAEC) do Laboratório Associado Centro de Estudos do Ambiente e do Mar (CESAM) da Universidade de Aveiro. Os seus interesses de investigação incluem, entre outros, estratégias de desenvolvimento relacionadas com a economia circular. A lista completa de vencedores deste prémio está disponível em spq.pt/premios/ramoa-ribeiro/lista.

\section{Bruno Machado}

brunofm@fe.up.pt

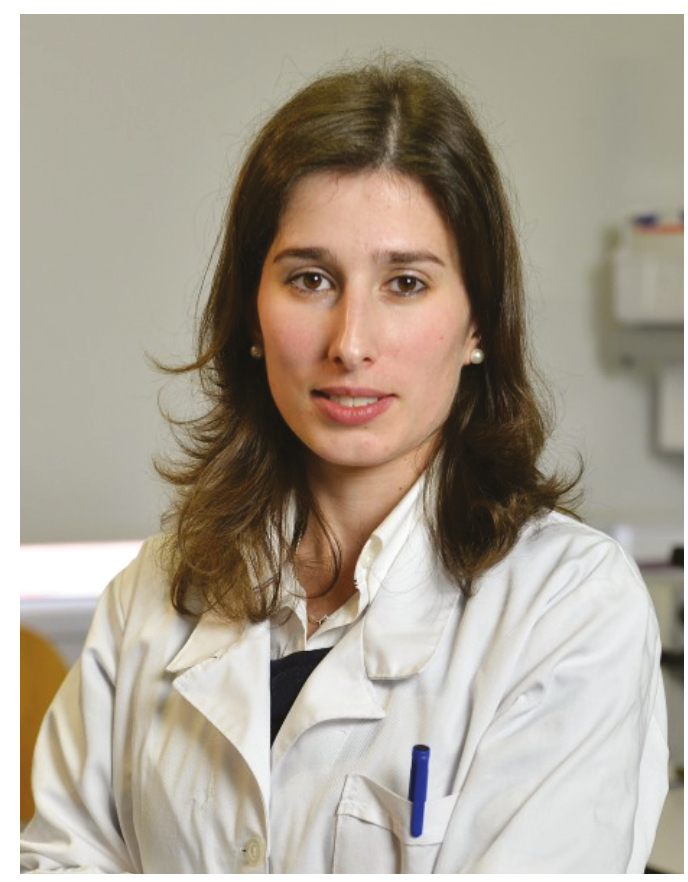

\section{Prémio EuChemS Lecture 2020 Atribuído a Victor Mougel}

O Prémio EuChemS Lecture 2020 foi concedido ao Professor Victor Mougel. Todos os anos são premiados os principais resultados atingidos por um investigador júnior que trabalha no campo da Química num país com uma organização pertencente à EuChemS.

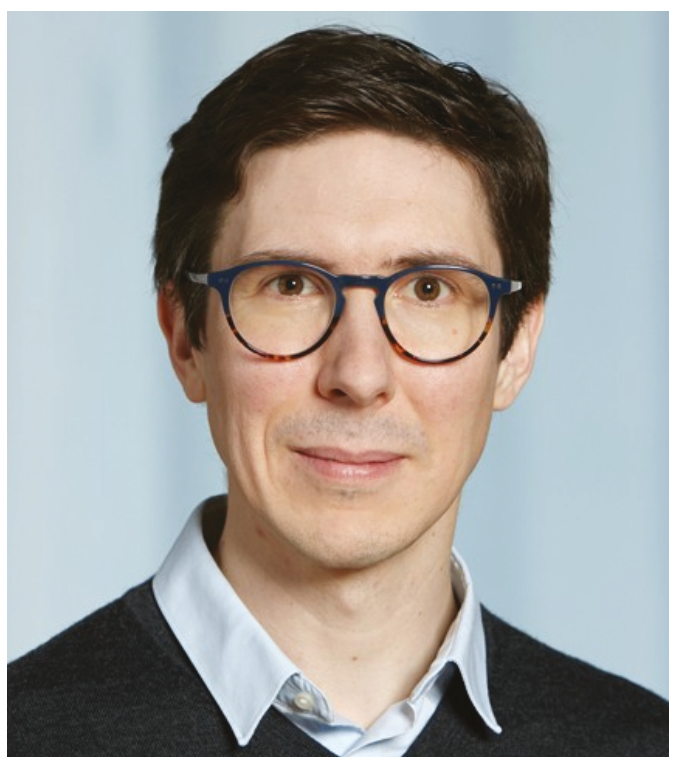

Victor Mougel é um químico francês e atualmente é professor de Química Inorgânica no ETH Zürich. Produziu contribuições relacionadas com o desenvolvimento da redução eletrocatalítica bioinspirada do $\mathrm{CO}_{2}$, um passo importante em direção a um armazenamento e conversão de energia mais sustentável. O trabalho de Victor Mougel abrange várias áreas de especialização, desde a compreensão dos processos fundamentais que ocorrem à escala molecular até ao design de materiais e a investigação das suas propriedades catalíticas em ambientes industriais. O Professor Victor Mougel também está envolvido na comunidade química enquanto ex-membro da Rede Europeia de Químicos Jovens (EYCN).

O premiado dará uma palestra plenária convidada no 8. ${ }^{\circ}$ Congresso de Química EuChems (ECC8) que decorrerá em Lisboa em 2022.

Mais informações acerca deste prémio disponíveis em euchems.eu/awards/lecture-award.

Bruno Machado

brunofm@fe.up.pt 